\title{
Data Driven Manufacturing: Challenges and Opportunities
}

\section{Hendro Wicaksono}

President Commissioner PT Labdha Teknika Nusantara (Greenlndonesia)

Professor of Industrial Engineering Jacobs University Bremen

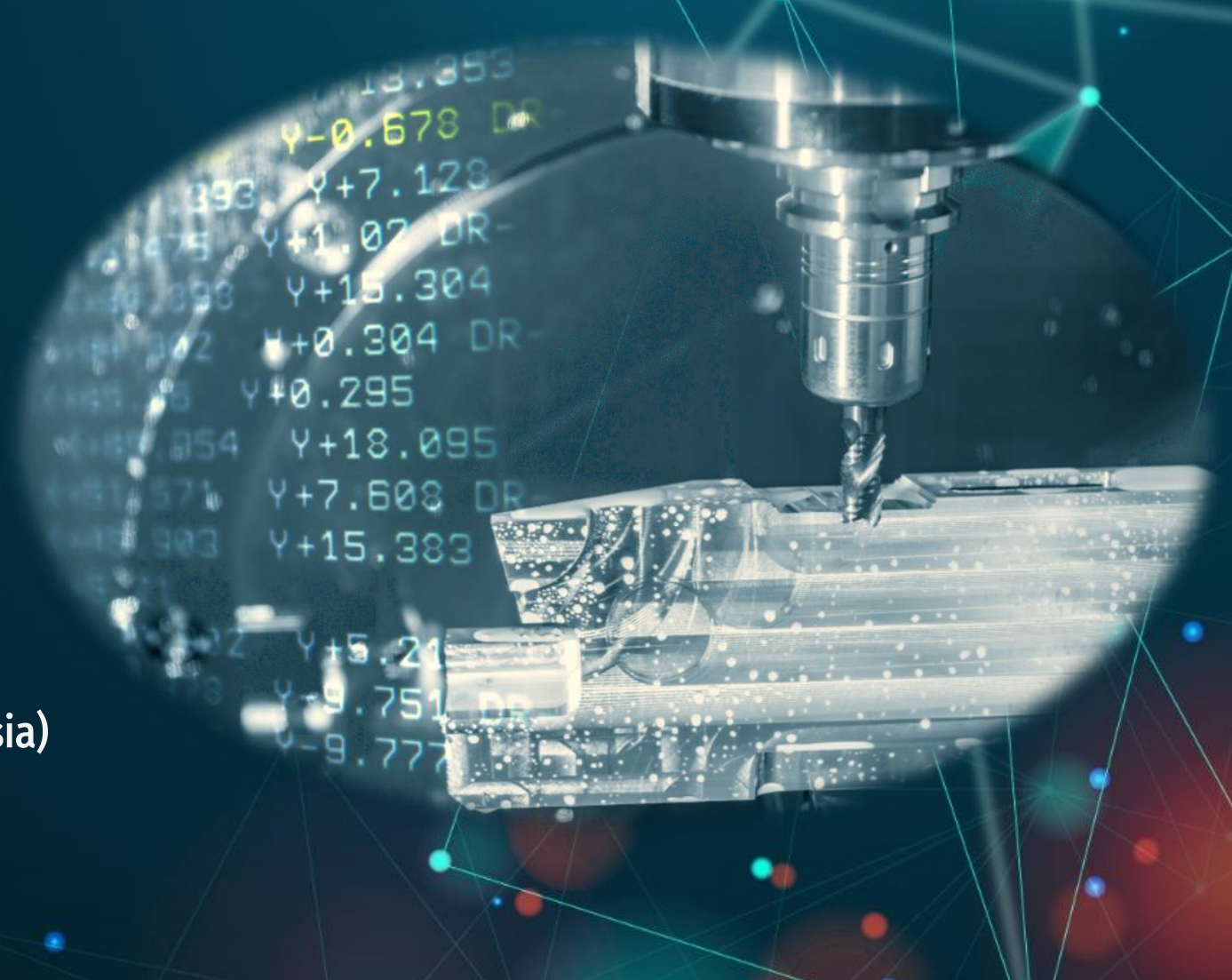




\section{OUTLINE}

01 Industry 4.0

$$
02\left\{\begin{array}{l}
\text { The Roles of Data } \\
\text { In Manufacturing 4.0 }
\end{array}\right.
$$

$03 \int \begin{aligned} & \text { Implications on Business and } \\ & \text { Manufacturing Operations }\end{aligned}$

04 Project Examples 
The Fourth Industrial Revolution Industry 4.0

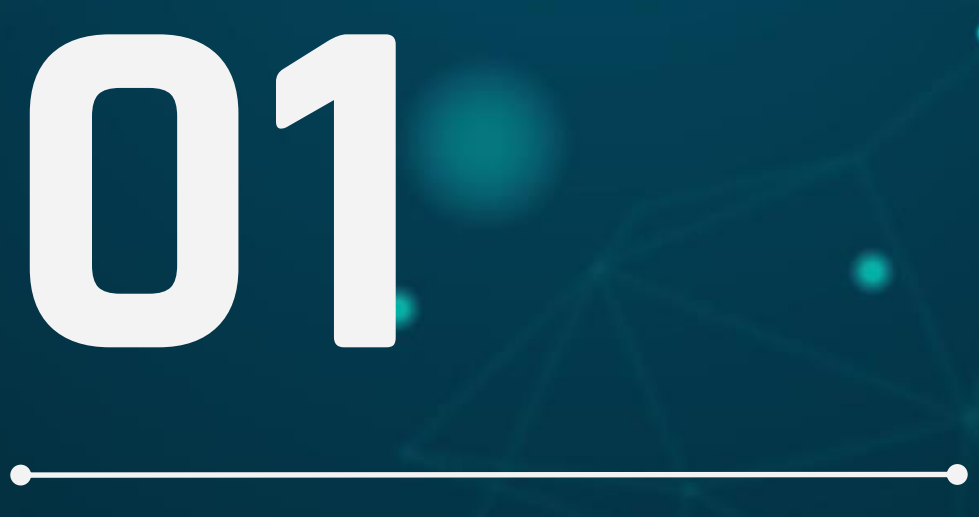




\section{What is industry $4.0 ?$}

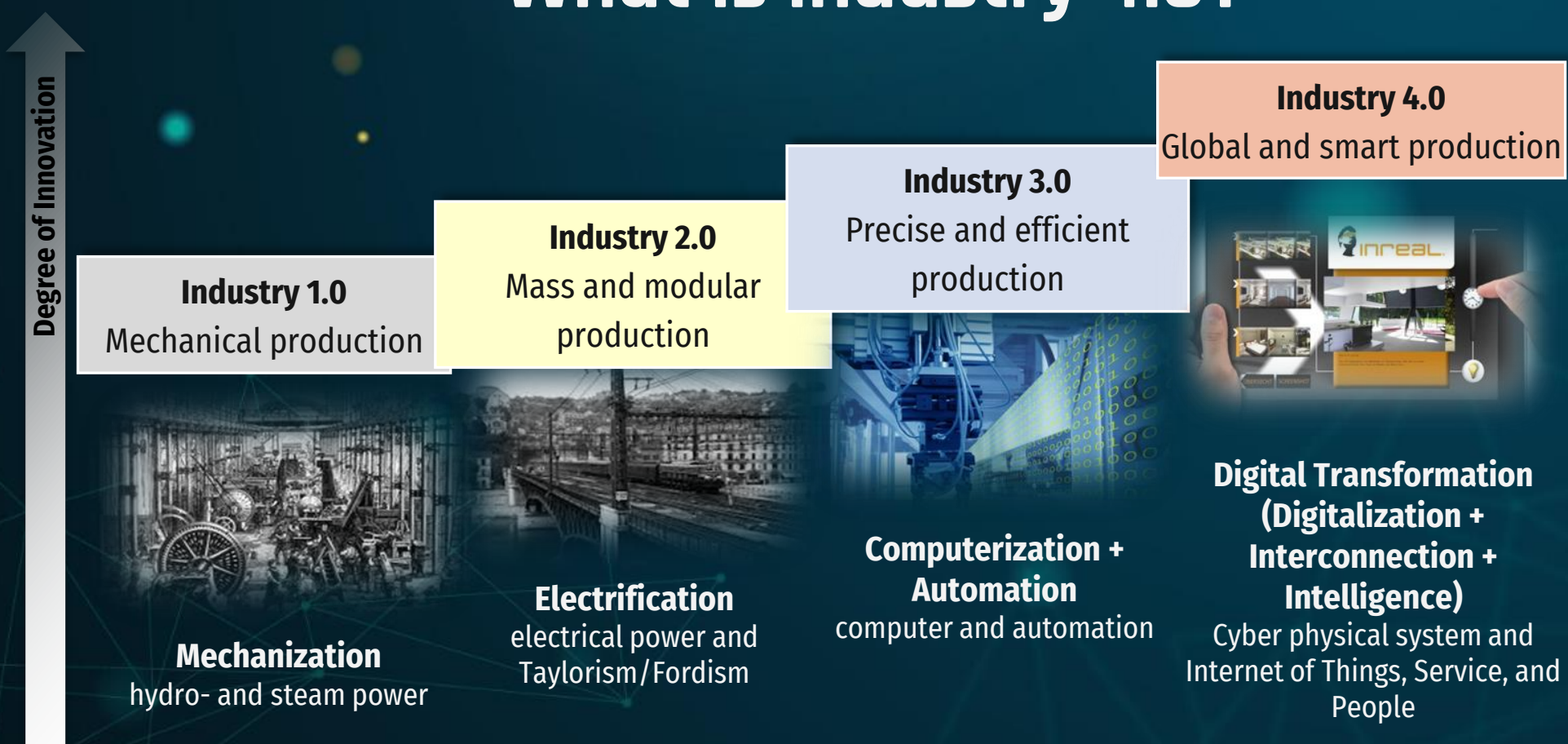




\section{Industry $\mathbf{3 . 0}$ vs. Industry $\mathbf{4 . 0}$}

\section{Drivers}

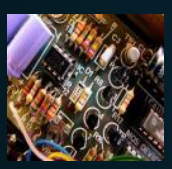

Advancements in electronics

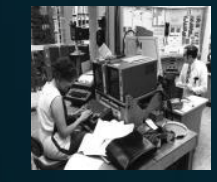

Commercial uses of computers
Computer-driven transformation
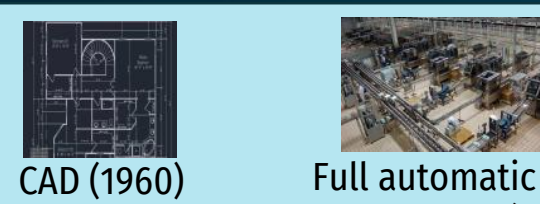

Full automatic production line (1969)

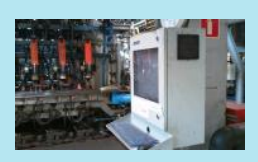

Computer Integrated

Manufacturing (1990)

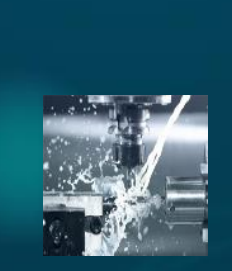

Higher quality and precision
Impacts

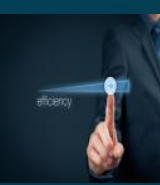

Higher efficiency

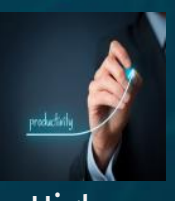

Higher productivity

\section{Drivers}

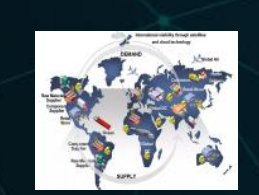

Global value chain

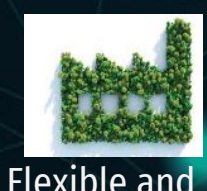

Flexible and green manufacturing

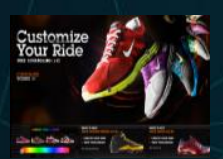

Product customization

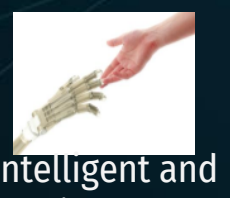
adaptive systems

\section{Digital transformation}

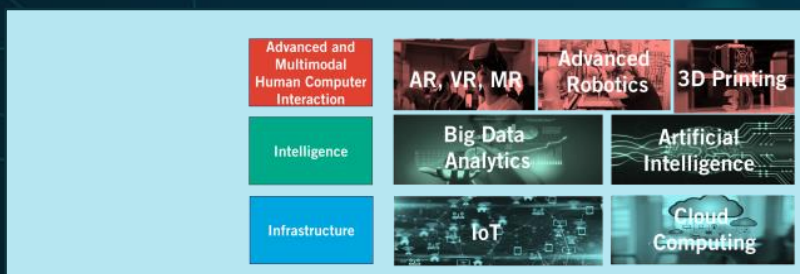

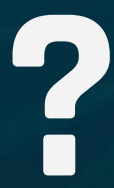




\section{Innovation focuses of industrial revolutions}
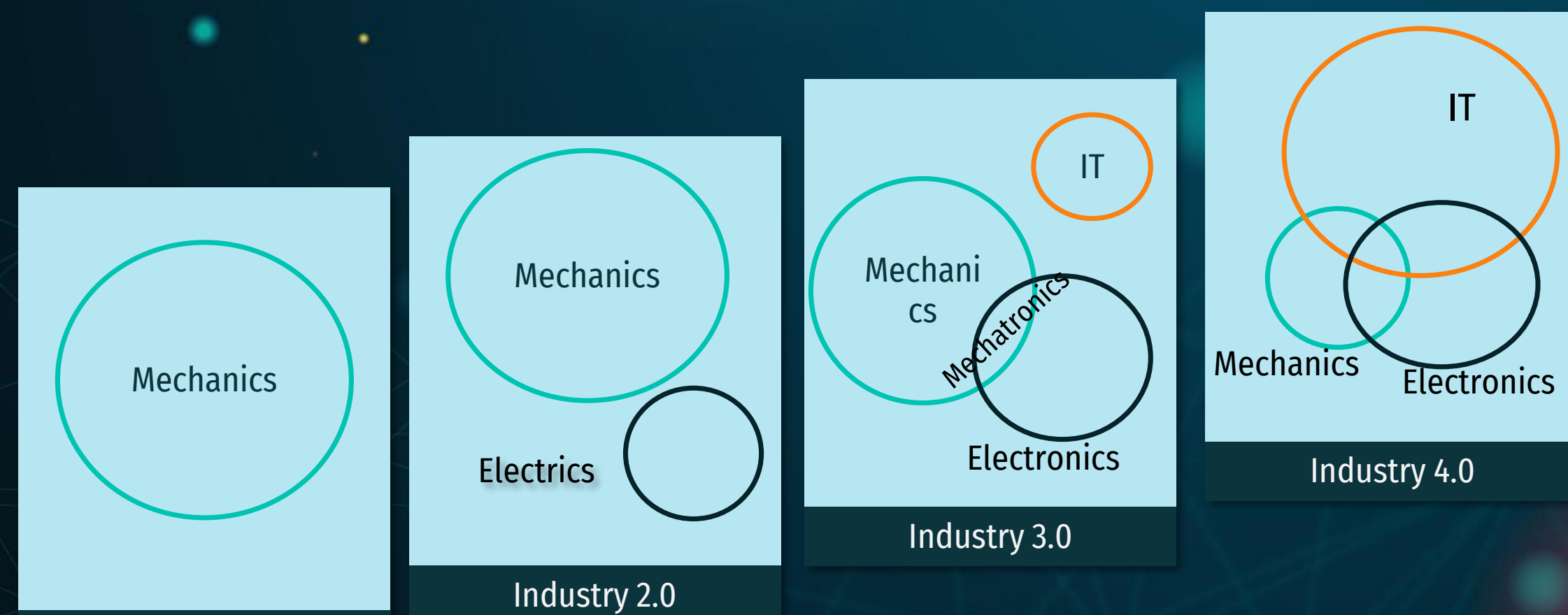

Industry 2.0

Industry 1.0 


\section{The industry 4.0 enabling technologies}

\section{Advanced and} Multimodal Interaction

Intelligence

Infrastructure and Interconnection
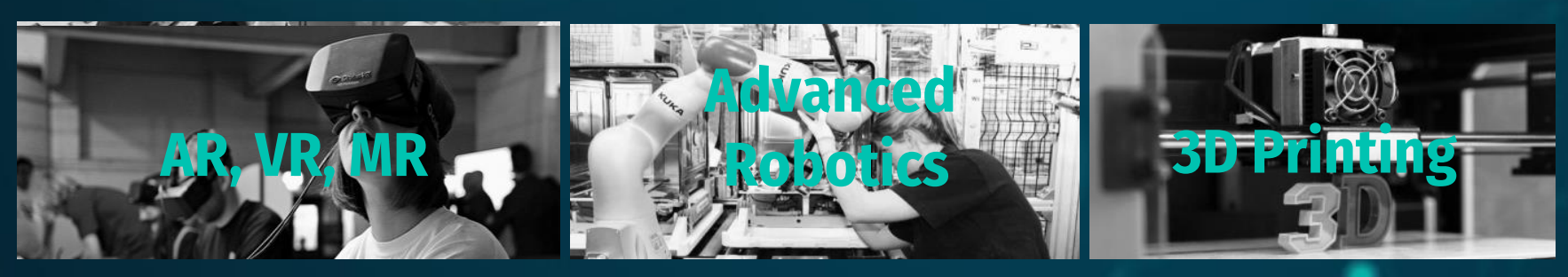

P

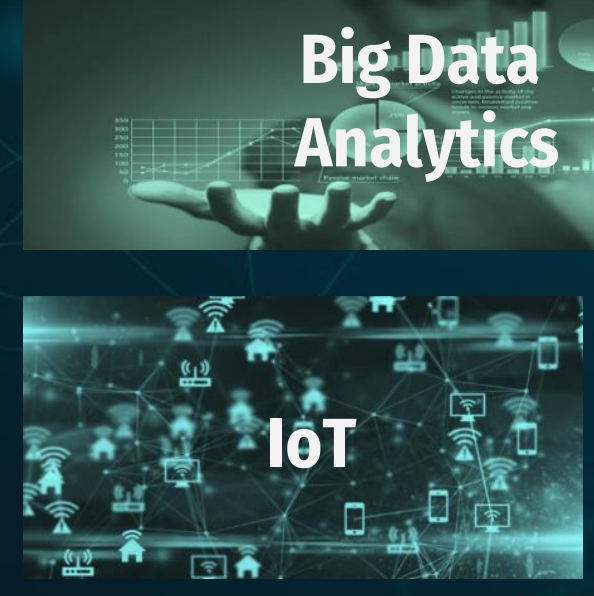

Artifica:
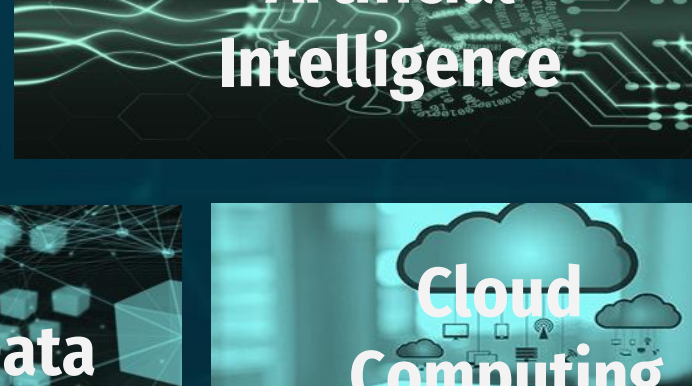

Lińcidata 
The Roles of Data in Manufacturing

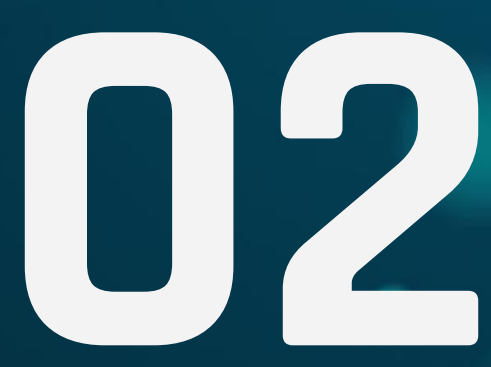




\section{Pillars of industry 4.0: from manufacturing (Smart PPR)}

Smart Process/ Operation

Smart Product

Q

(a)

(8)
丒

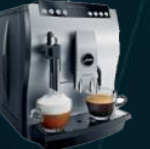

(Q)

(1)

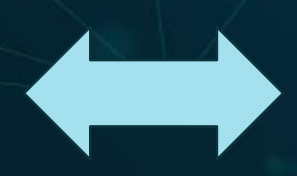

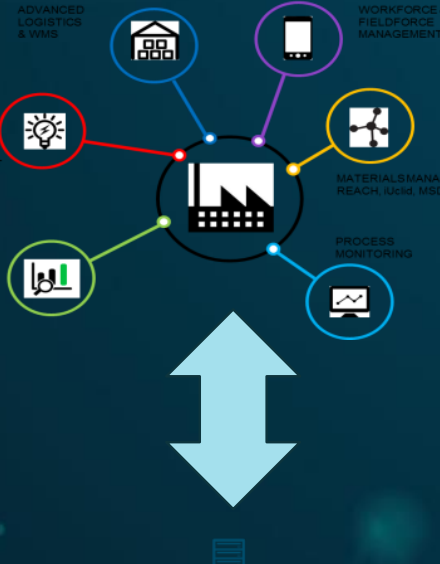

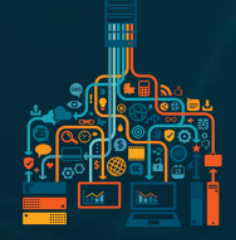

Data Driven Service
Smart Resource/ Infrastructure

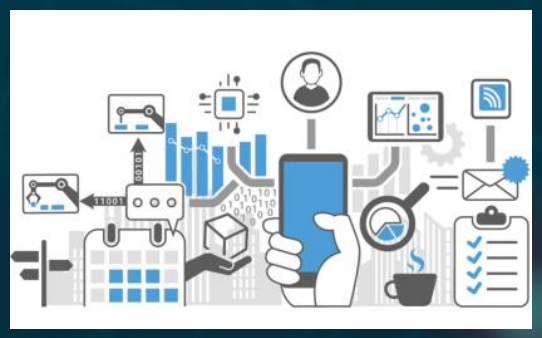

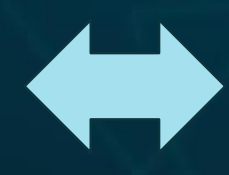


$\times 4.0$

Industry 4.0 


\section{Agriculture 4.0}

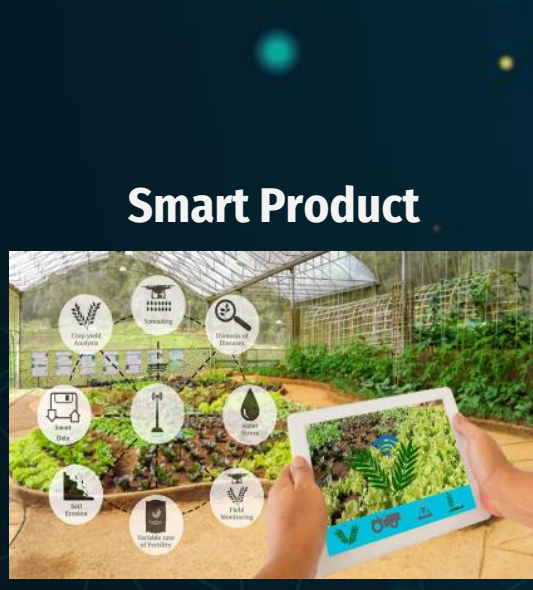

Self informing crops

\section{Smart Process/ Operation}

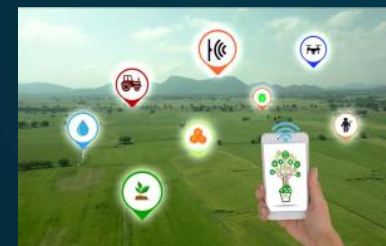

Connected farmers, suppliers, market

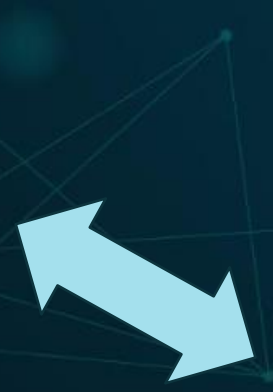

\section{Smart Resource/ Infrastructure}

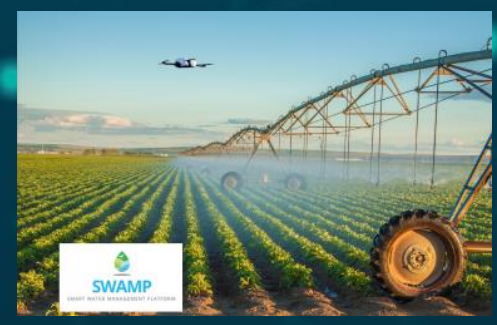

Automatic watering, smart transport, smart warehouse
Data driven service

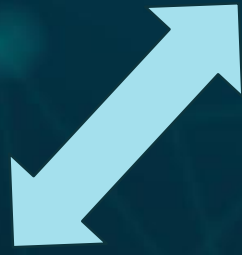

1 㬡

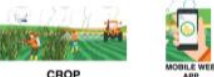




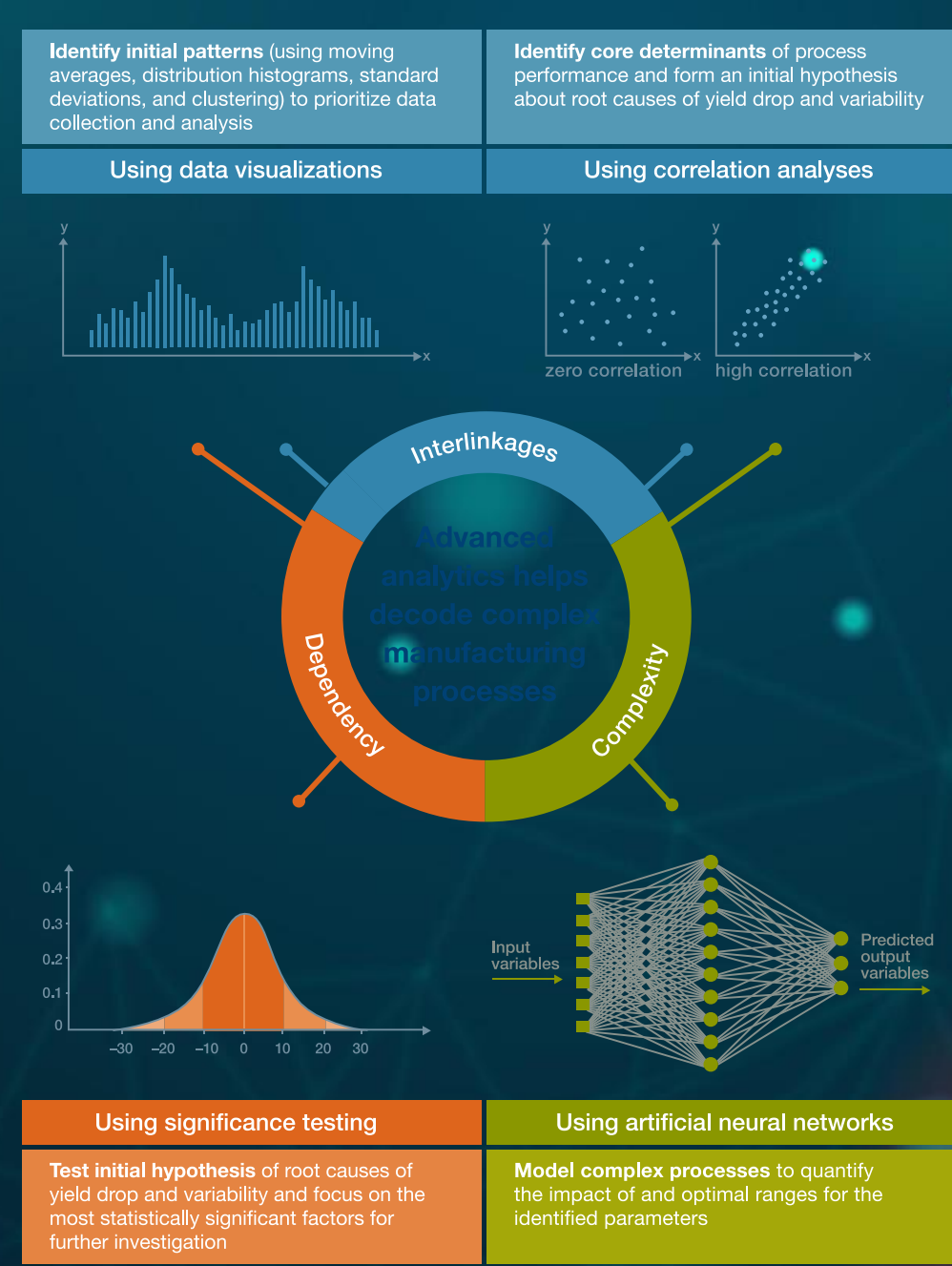




\section{Implications on}

Business and Manufacturing Operations

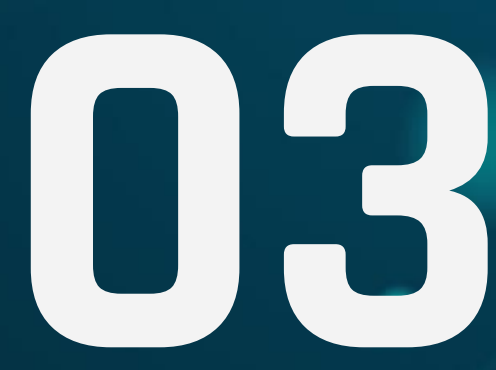




\section{What are the benefits of big data for manufacturing?}

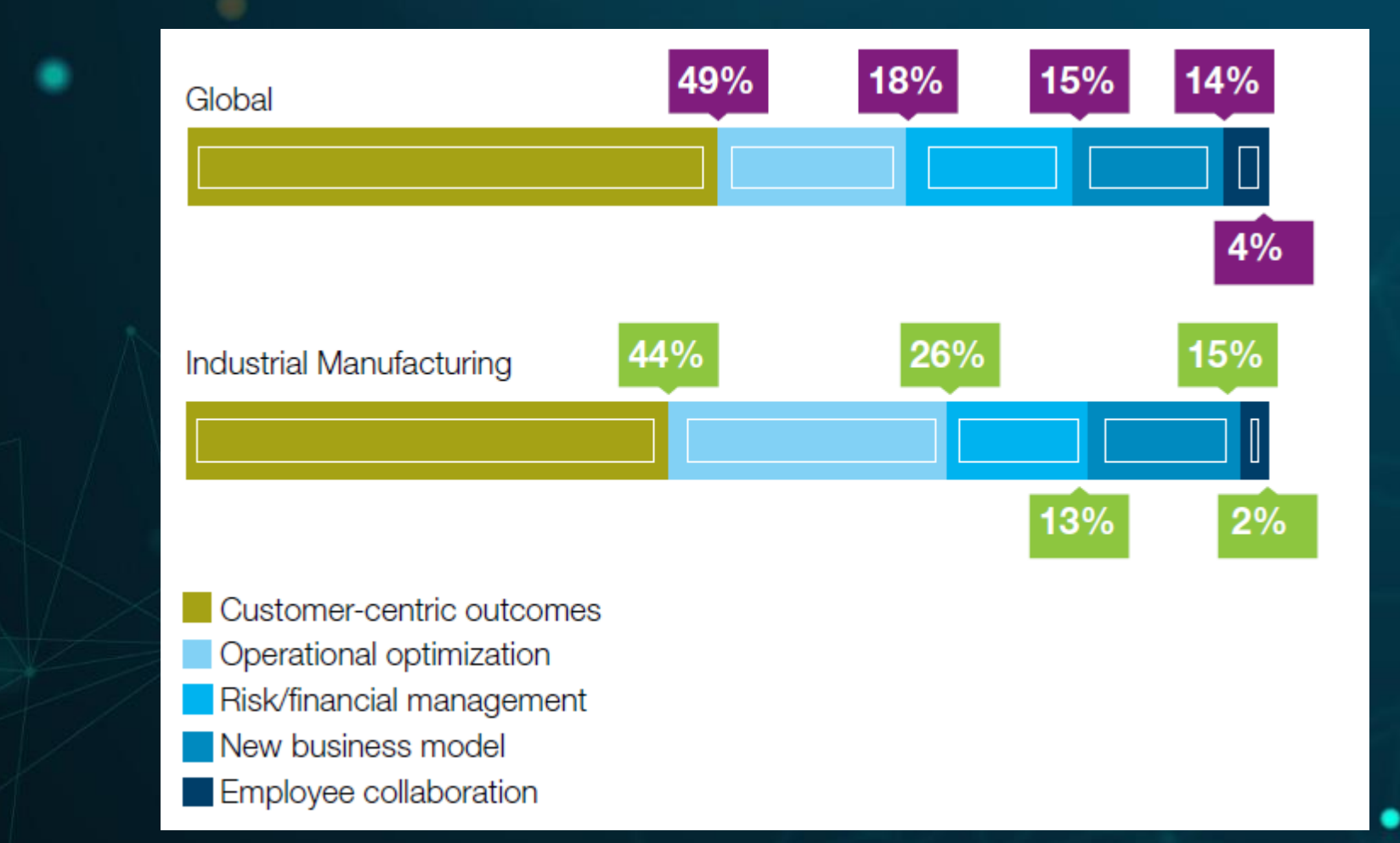




\section{Data sources, infrastructure, and analytics.}

Data Sources

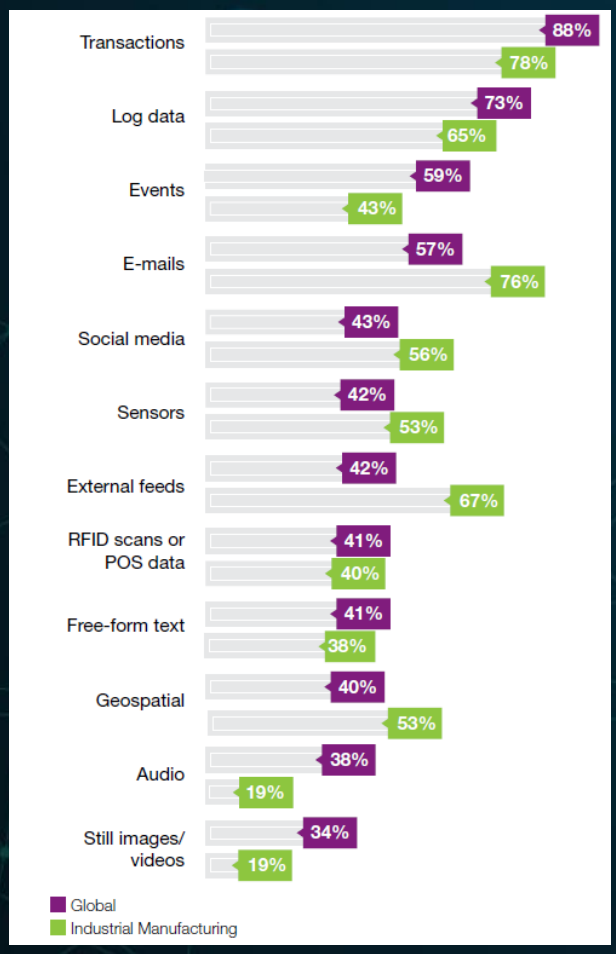

Data Infrastructure

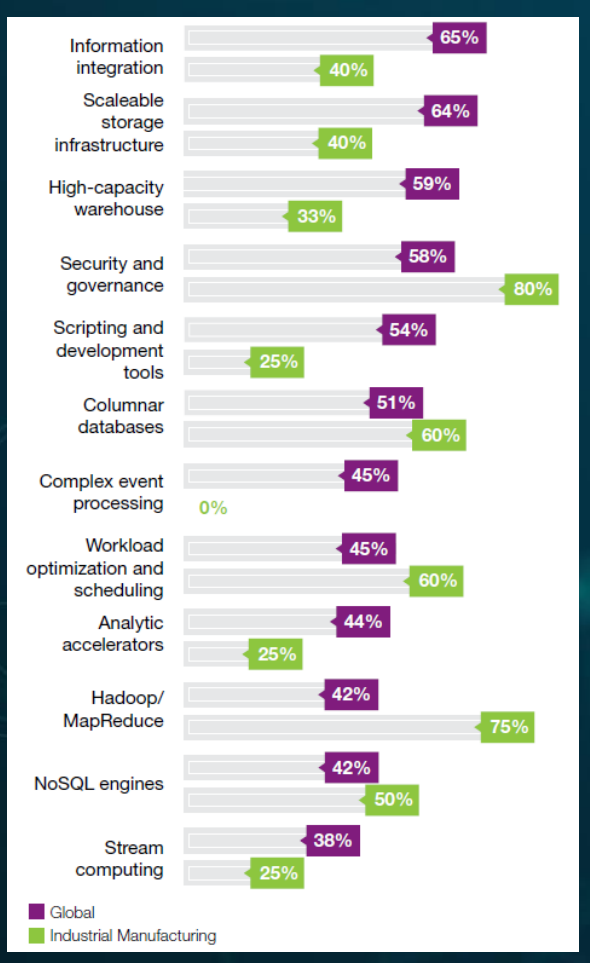

Analytics Methods

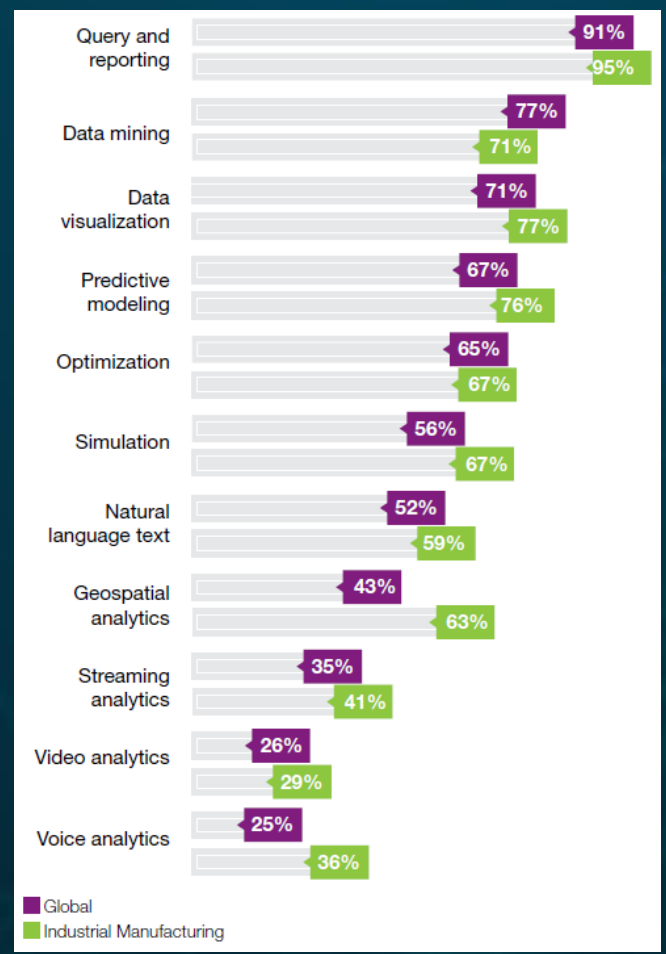




\section{Data driven operational optimization}

\section{Smart Design}

Market and demand analysis

Transaction, demand, user behavior data

Material tracking

Awareness of material shortages

proactive distribution

BOM, material quantity, distribution data

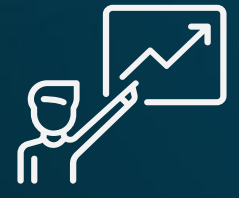

90
Smart Planning and Optimization Production planning and optimization Order, capacity, process data

Process and Condition Monitoring

Facilities and capacity monitoring

Equipment parameters, production schedule, resource loading

\section{Smart Maintenance}

Predictive maintenance and energy optimization
Quality tracing and management

Quality criteria, quality test, production process data

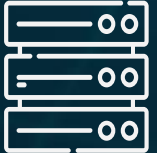




\section{Customer-centric outcomes: data driven serviçes}
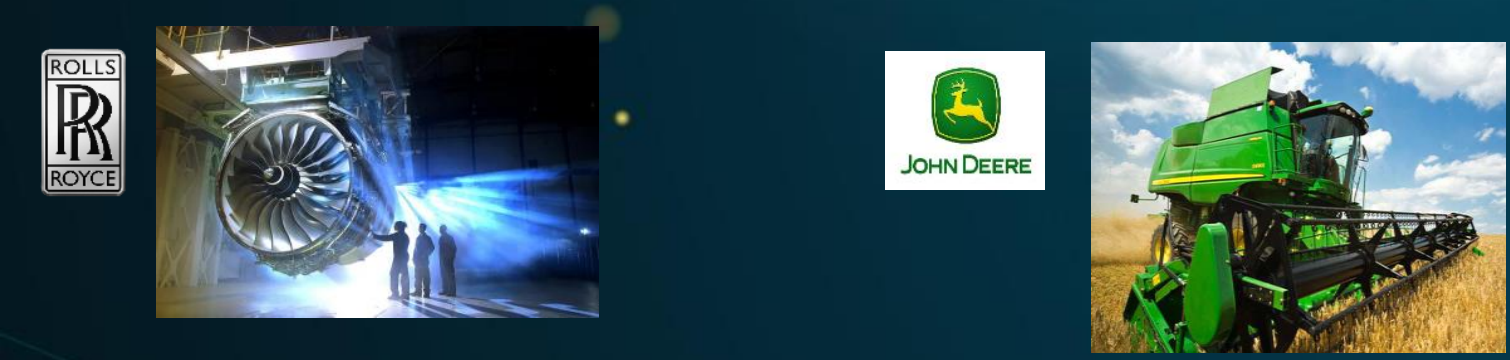

RALPII L ILREN

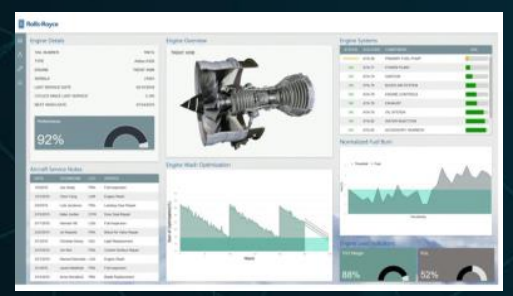

Airplane engine + real time monitoring, predictive maintenance, optimization service

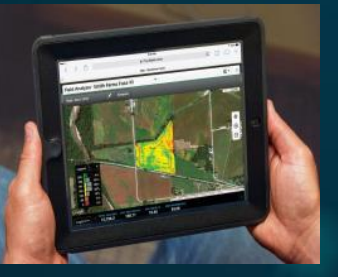

Farming machines +

Farm monitoring, social media https://myjohndeere.deere.com
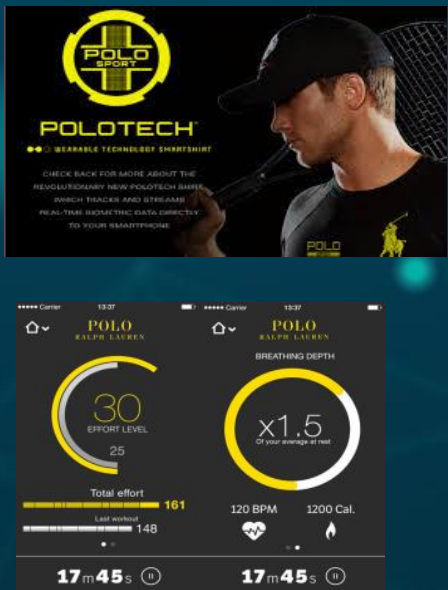

Sport shirt + Health monitoring, early warning system 
Project Examples

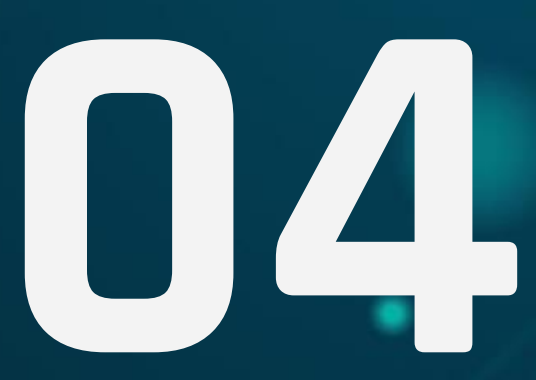




\section{Project Ecobalance}

- Sensor network to collect data (power consumption, machine states, surrounding factors)

- Power consumption prediction for individual processes and products through machine learning

- Energy optimized production planning and scheduling

- Peak load avoidance

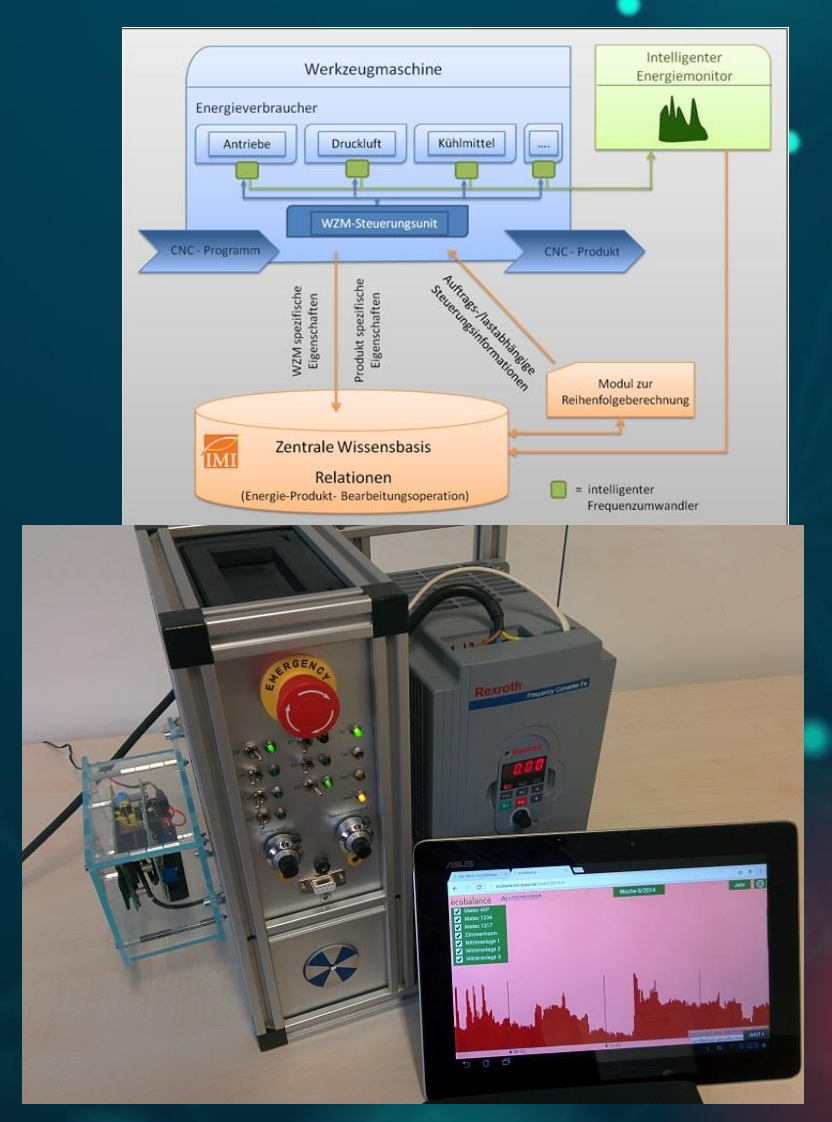




\section{Demand Response (DR)}

The goal of DR is to shift the peak demand (red) to the peak time of availability of renewable energies (yellow).

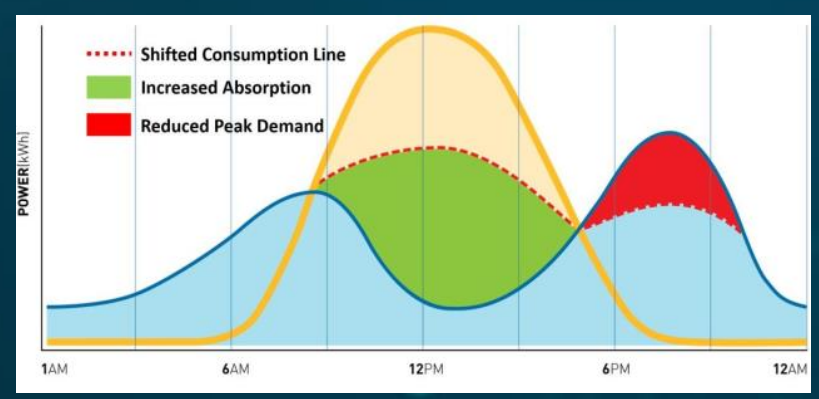

The power consumption is shifted from red to green, (green) shows the decrease of energy waste.

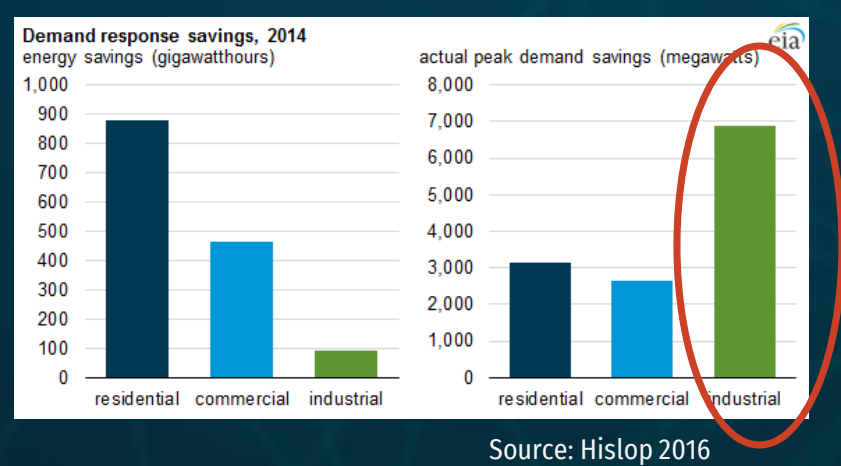

DR has the potential to access $160 \mathrm{GW}$ of flexible capacity by 2030. This reduces energy supply costs by up to 50 billion euros.

The industrial sector produces the highest real savings in peak demand 


\section{Project Delfine}

\section{Delfane}

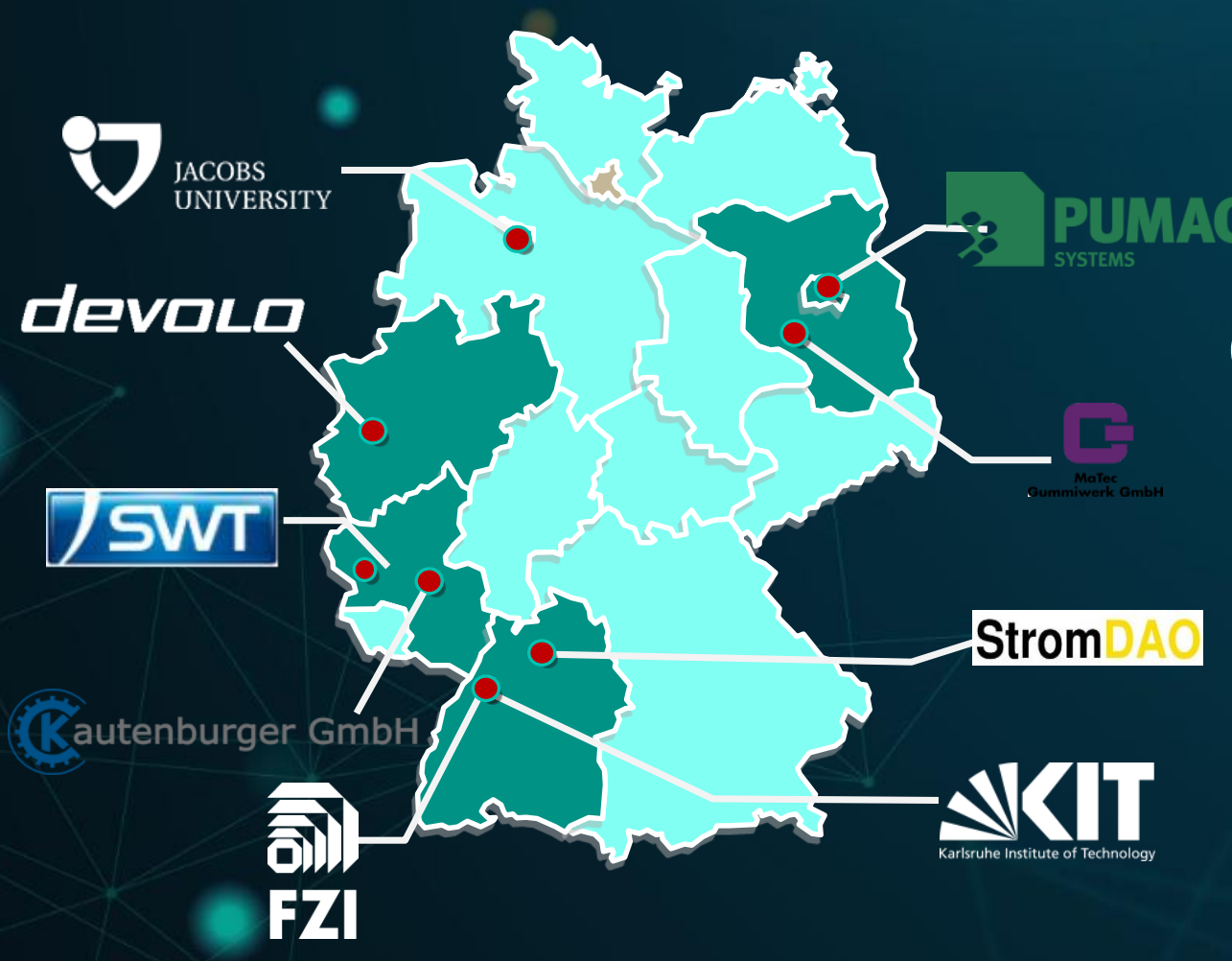

Generation

\section{Consumption is managed \\ by generation \\ Demand Response}

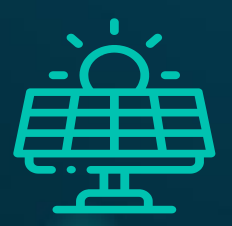

Consumption
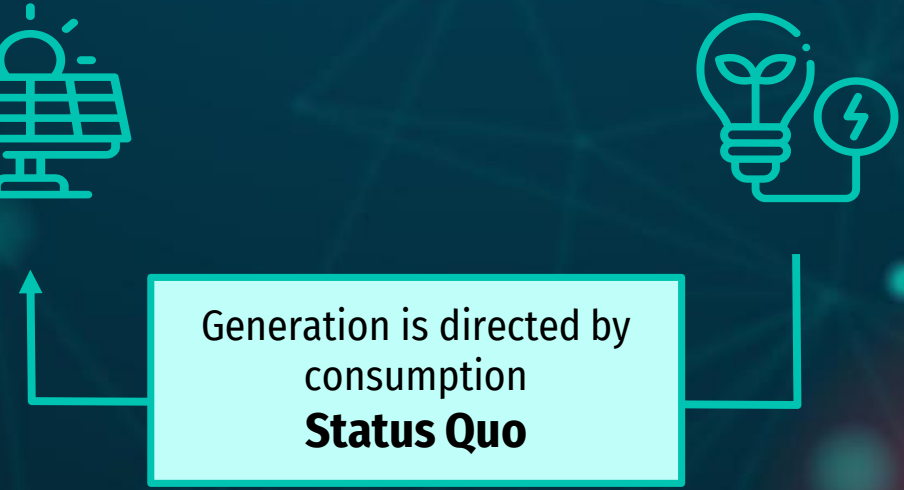

Generation is directed by consumption Status Quo 


\section{Project Solution}

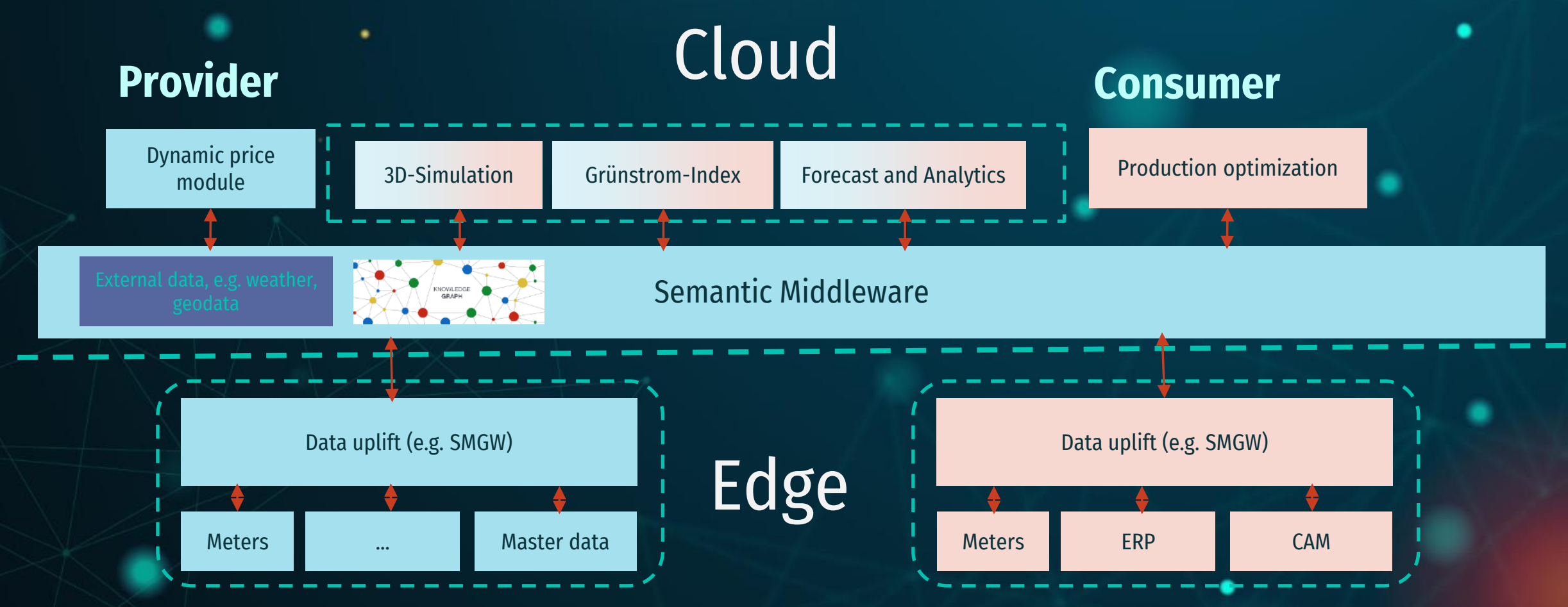




\section{Project Smart Data Web}

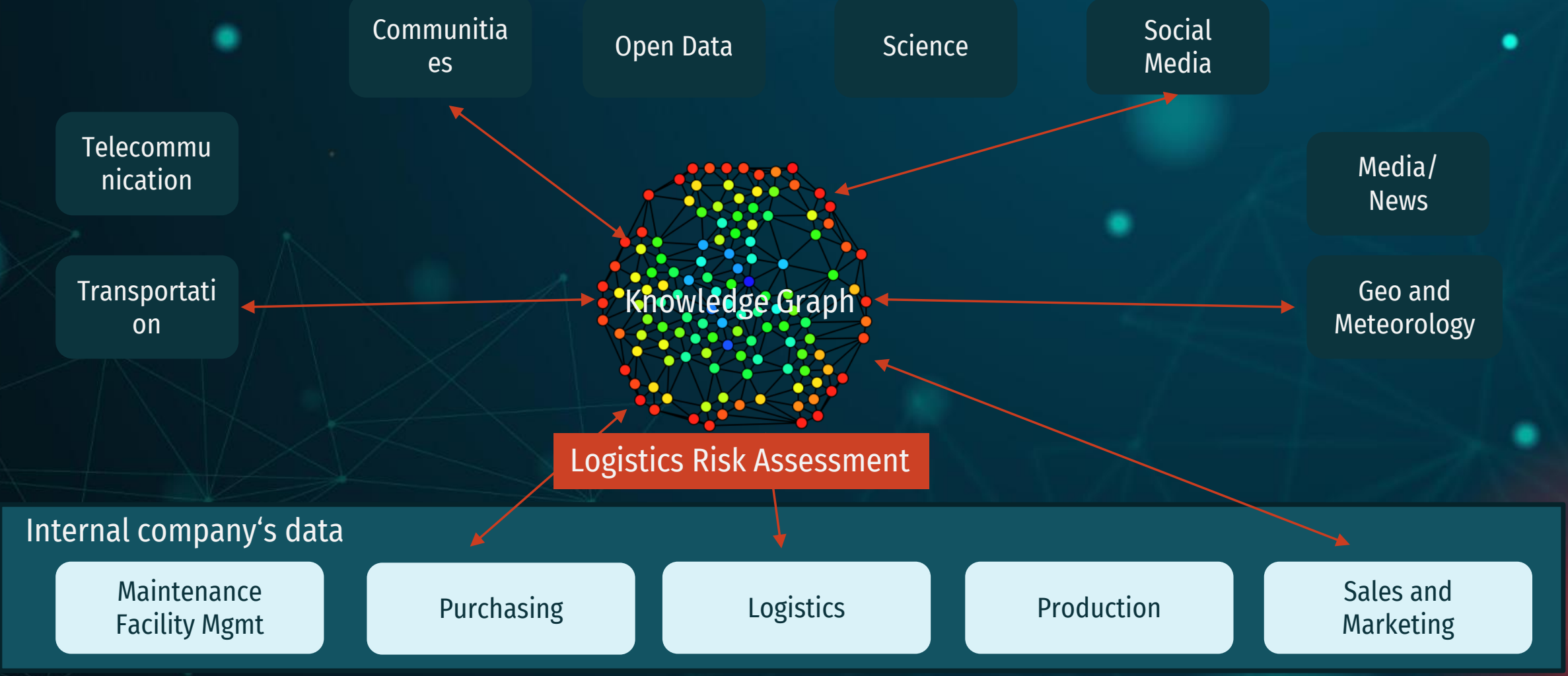




\section{Projects about big data for environment}

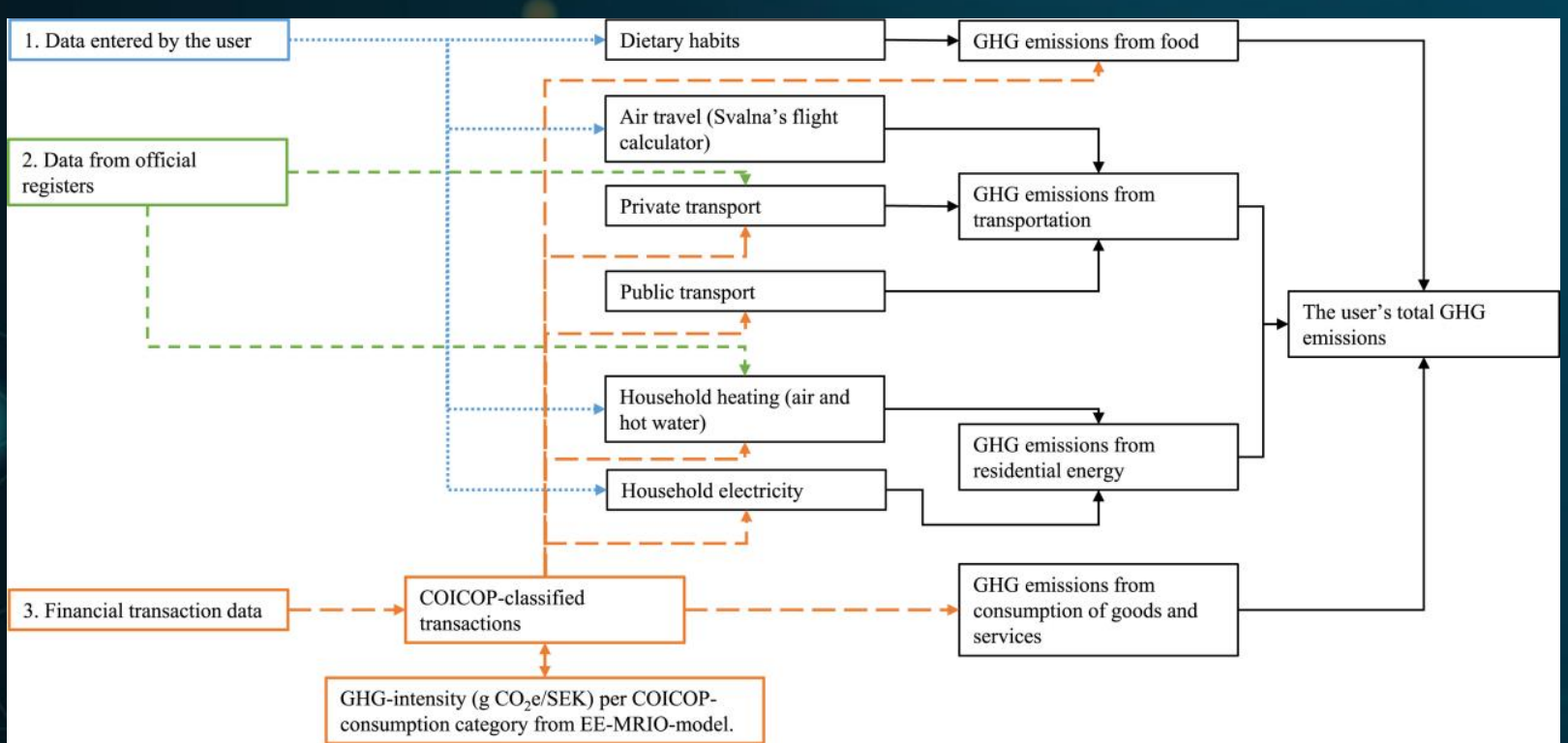

Project Svalna:

Calculate carbon footprints of individual products and processes
BUSINESS \& FINANCIAL NEWS | July 28, 2020

BASF calculates $\mathrm{CO} 2$ footprint of all sales products

- BASF as the first chemical company with transparent emission data for the entire portfolio of approximately 45,000 products 


\title{
THANK YOU!
}

\author{
hendro.wicaksono@green-indonesia.com \\ h.wicaksono@jacobs-university.de \\ +49 17623910735 \\ www.green-indonesia.com \\ indeed.user.jacobs-university.de
}

\section{(C) @greenindonesiaofficial \\ (i冈⿴) @hendrowicaksono \\ (5) @greenindonesiaofficial}

CREDITS: This presentation template was created by Slidesgo, including

icons by Flaticon, and infographics \& images by Freepik.

Please keep this slide for attribution. 